\title{
Minicrash tests biotechnology investors and companies as market fluctuates
}

The mini stock market crash that started in Asia in October was a good test of the robustness of worldwide investor attitudes toward biotechnology company stocks. In the past the prices of biotechnology company shares have been prone to rise and fall wildly, reflecting investor uncertainty or ignorance about biotechnology. There was still evidence of residual "volatility" this time, but hardly more so than in other comparable sectors.

The American Stock Exchange biotechnology index (Amex BTK), which tracks stocks from 15 of the larger US biotechnology companies, including Amgen (Thousand Oaks, CA), Biogen (Cambridge, MA), Centocor (Malvern, PA), and Immunex (Seattle, WA), dropped nearly $10 \%$ on Monday, October 27, the day the minicrash hit the New York exchanges. The all-industry Amex composite index, in contrast dropped only $5.8 \%$. In the week of the crash (October 27-31), the Amex BTK fell nearly twice as much as the Amex all-industries index (7.7\%, compared to $3.6 \%)$. Over the same week, the another US biotechnology index, comprising Nasdaq-listed companies, was down by $4.2 \%$.

However, stock analyst David Stone of Cowen \& Co. (New York), notes that although biotechnology stocks did fare worse than the general market, the poor performance was not peculiar to biotechnology. Stocks of similar size and trading volume, regardless of industry, behaved in the same way. This is supported by the drop in the Nasdaq biotechnology index-only marginally worse than that of the Nasdaq industries index, which fell by $4.1 \%$.

A number of companies bucked the downward trend. Amgen, not surprisingly, weathered the storm, its stock price improving $2 \%$ over the week. Genzyme was also up $2 \%$, and Geltex Pharmaceutical (Waltham, MA) rose $5 \%$. A big rise-of $20 \%$ - however, came from ViroPharma (Malvern, PA), an antiviral drug development company currently focused on developing drugs aimed at the common cold.

There were some tumblers, too, of course. Immunex fell $13.3 \%$ on Monday of the crash and finished the week $14.7 \%$ down. Matrix Pharmaceuticals (Fremontark, CA) fell $12.3 \%$ over the week, while Chiron (Emeryville, CA) and Creative Biomolecules (Hopkinton, MA) both dropped around 9\%.

The crash hit European exchanges a day later. By the Tuesday close, the BancAmerica Robertson Stephens (BARS) Biotechnology Index (Europe), which tracks 29 European biotechnology companies, including British

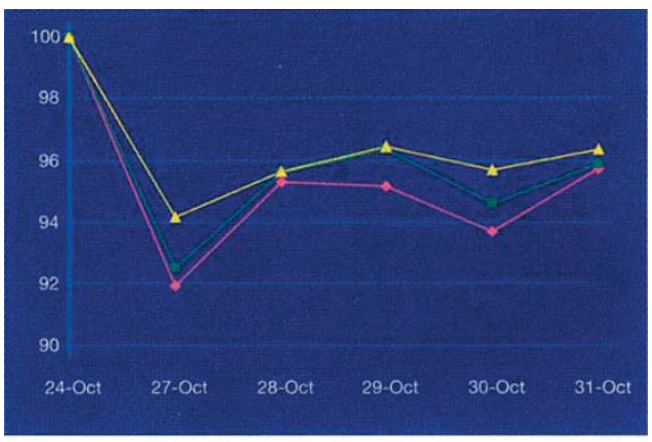

US biotechnology stocks fared only marginally worse than all-industry and composite stocks. Nasdaq biotechnology index (pink), Nasdaq industries index (green), Amex composite (yellow).

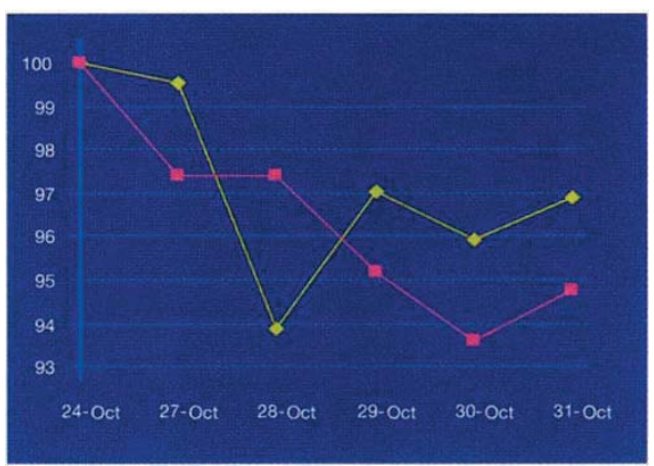

In Europe, biotechnology stocks outperformed composite stocks. BARS biotechnology index (yellow), FT-SE Eurotrack 200, pink.

Source: BancAmerica Robertson Stephens.

Biotech (Oxford, UK), Chiroscience (Cambridge, UK), Genset (Paris), and PPL Therapeutics (Roslin, UK), had plunged $6.1 \%$. That was over twice the $2.6 \%$ fall of the FT-SE Eurotrack 200, a composite index of 100 European companies. Nick Woolf of Robertson Stephens (London) characterized this as "a flight to safety" by investors withdrawing from more speculative investments and moving into established companies.

However, by the end of the week, investors had apparently "flown" back to European biotechnology companies, with the BARS index drop of $3.1 \%$ during the week comparing favorably to the $5.3 \%$ drop in the Eurotrack. One explanation may be that any "adjustments" in the markets for biotechnology stocks in Europe may have occurred in earlier weeks, as European companies trotted out their "bad news."

Over the past six months, the BARS index has dropped several times. In July, when British Biotech extended the phase III trial of its most advanced product, Zacutex for pancreatitis, the BARS index fell $4.6 \%$. On September 9 , it fell $5.5 \%$ when it became clear that the deal between biocoatings specialist Biocompatibles (Uxbridge, UK) and Johnson \& Johnson (New Brunswick, NJ) was less favorable than had been thought. The index may, therefore, have been at a highly "realistic" level when the crash came. That didn't stop British Biotech's stock price from falling to its lowest point since October 1995, however; it lost $14.5 \%$ over the week. "Sentiment in the [biotechnology] sector has been bad for some time," says Woolf. "Performance of the Eurotrak index for the previous second and third quarters has certainly been a lot better than the biotechnology index."

Genset, France's big hope in genomics, fared better. After an initial drop of nearly $10 \%$, Genset recovered just under half of it lost value by the end of the week. And encouraging for the German biotechnology industry was the performance of Qiagen NV (registered in Venlo, the Netherlands), a specialist in the separation and purification of nucleic acids. Although it initially suffered one of the biggest drops seen anywhere $(14.9 \%)$, by the end of the week it was up $1.4 \%$. Woolf believes that investor confidence in Qiagen could be due to its recent listing on Frankfurt's Neuer Markt (Nature Biotechnology 15:1230, 1997).

David Stone speculates that the minicrash may actually be healthy for biotechnology in the long run, "forc[ing] investors to reflect on where the sources of value are." During a crash, investors withdraw money from all markets; there are no "safe stocks." Stone argues that with this in mind, when they reinvest, investors may look more carefully for bargains in what are traditionally volatile and speculative investments.

Emma Dorey

As Nature Biotechnology went to press, US biotechnology stocks were tumbling again. By November 13, the Nasdaq biotechnology index had already dropped almost to its low during the week of the crash, and the Amex biotechnology index had fallen a further 3\% below its trough that week. 